\title{
Gestalt-Terapia e Terapia Sistêmica: \\ O CORPO EM PSICOTERAPIA
}

Marília Toscano de Araujo Gurgel ${ }^{\star}$

\begin{abstract}
Resumo
Este trabalho demonstra a contribuição da abordagem corporal da GestaltTerapia para a Terapia Familiar Sistêmica. O método utilizado foi a gravação de uma oficina de corpo estruturada em saberes das duas abordagens. A oficina proporcionou, a cada participante, maior qualidade de atenção, presença, contato e criatividade, uma forma mais integrada de construir sua identidade. O entrecruzamento das duas abordagens trouxe às pessoas maior consciência de quem são e como são no "mundo", ajudando-as no processo de assunção da história que contam. A experiência mostrou aos terapeutas as possibilidades que o trabalho corporal oferece como método de apreensão da realidade co-construida.
\end{abstract}

Palavras-chave: Consciência. Família. Gestalt-Terapia. Terapia Sistêmica.

\section{Gestalt-therapy and Systemic Therapy: THE BODY IN PSYCHOTHERAPY}

\begin{abstract}
This work demonstrates the contribution of the body approach in the GestaltTherapy to the Systemic Familiar Therapy. The method used was a tape recorded in a body workshop structured according to the both approaches. The workshop gave the opportunity to each member a more integrated form of constructing their own identity. The intercrossing of both approaches brought to the persons, better awareness of who and how they are in the "world", helping them in the process of assumption of the story they tell. The experience shows to the therapists, the possibilities that the bodywork gives to a comprehensive method of constructed reality.
\end{abstract}

Keywords: Awareness. Family. Gestalt-Terapy. Terapy Systemic.

\footnotetext{
^ Aluna da Pós-graduação em Saúde Mental do Instituto de Psiquiatria - IPUB/UFRJ. Endereço: Av. Venceslau Brás, 71 Fundos. CEP: 22290-140. Rio de Janeiro - RJ - Brasil. Apoio Técnico: Núcleo de Audio Visual do Instituto de Psiquiatria- IPUB/UFRJ.

E-mail: mariliathoscan@gmail.com
} 
O presente artigo diz respeito a uma experiência terapêutica feita no Instituto de Psiquiatria da UFRJ/IPUB. Nela, conjugaram-se resultados de pesquisas com o corpo a uma prática terapêutica já existente: a terapia Sistêmica de Família. A partir dessa articulação, avançou-se em direção a uma forma de trabalho terapêutico capaz de apontar novas possibilidades; uma forma de atuação em que se leva em consideração o corpo no tratamento de transtornos psíquicos. Tal forma de atuação, portanto, baseou-se na conjunção de dois enfoques teóricos e práticos, a terapia sistêmica de família e a consciência corporal, que, no caso, teve suporte teórico da Gestalt-Terapia.

A Gestalt-Terapia é uma abordagem em psicoterapia que se utiliza do consciente como instrumento de trabalho de busca da emoção. Nessa abordagem, acredita-se que em contato consciente com a emoção, ou melhor, com seus conteúdos, o sujeito pode entrar no sentimento que o mantém preso em sua problemática relacional. A Terapia Sistêmica, já praticada no IPUB, utiliza-se do método de fazer "perguntas circulares" aos membros da família ou grupo, de modo que as informações a respeito de cada um circule por todos. Assim, trabalha-se também com um tipo de tomada de consciência, agora prevalentemente intelectual. Emoção e intelecção, importantes elementos em psicoterapia, são formas que, integradas, dão consistência ao material trazido, possibilitando ao cliente um estar pleno de sua atuação no mundo, responsabilizando-se por ela. A conjugação desses dois elementos nos parece distante da realidade da doença psiquiátrica, visto que nesta o sujeito está impossibilitado de movimentar-se intelectual e emocionalmente de forma livre e responsável. O que não acontece com a mesma intensidade em seus familiares, que, apesar de também fazerem parte da estrutura dos sintomas, como explica a visão holística, tanto da Gestalt, quanto da terapia Sistêmica, não estão mergulhados nele de forma inconsciente, como ocorre com os indivíduos acometidos por transtornos psicóticos. Portanto, a conjugação das duas abordagens em psicoterapia mostrou-se para nós um importante instrumento para trabalhar com familiares de pacientes psiquiátricos.

Isto se revelou na experiência de uma oficina de corpo, cujo o espaço foi aberto para tocar a emoção, o corpo, e também para pensar os sentimentos surgidos, a possibilidade de fazer a escolha de continuar ou mudar os movimentos da vida. Temos, então, a introdução de um trabalho de consciência corporal, prevalentemente emocional, em uma prática terapêutica verbal.

\section{Falando sobre a Pesquisa}

A pesquisa a que se refere o presente artigo foi feita em um grupo de mulheres, mães de pacientes de um Instituto de psiquiatria e usuárias do setor de família desse hospital. O fato de essas mães serem vistas como usuárias do serviço diz respeito ao reconhecimento de que fazem parte da saúde e da doença de seus filhos. Esta idéia veio acompanhando o surgimento da terapia familiar ao mesmo tempo em que faz parte de uma mudança de paradigma das ciências, uma mudança que vê os elementos do sistema como interligados e interdependentes, que reconhece os membros da família como co-responsáveis 
por suas dificuldades e é o que caracteriza a prática da terapia familiar feita no IPUB como Terapia Sistêmica de Família. Além disso, diferenciando-se de outras práticas de Terapia Sistêmica, caracteriza-se como Construtivista/Construcionista social, pelo fato de basear-se em estudos que consideram a linguagem e a comunicação como uma construção social. A comunicação vista sob esta perspectiva, faz da terapia familiar um espaço de transformação da realidade, por meio da transformação da linguagem.

Na medida em que trazemos para a Terapia Sistêmica de família (verbal) contribuições de estudos do corpo, acrescentamos um novo instrumento de comunicação: a linguagem corporal. A linguagem corporal aparece, nessa prática terapêutica, associada ao exercício de tomada de consciência da Gestalt e é isso que transforma o corpo em informação de conteúdos emocionais, que são trazidos para a consciência do mesmo modo que ocorre na terapia Sistêmica, com a utilização de perguntas, ${ }^{2}$ que, no entanto, estarão mais voltadas para os sentimentos e sensações corporais do que para a reflexividade, como ocorre na Terapia Sistêmica verbal. O jogo de informações, verbais ou corporais, relativos a cada elemento do sistema é o que propiciará seu movimento e sua mudança.

\section{A OFICINA DE CORPO DE FAMILIARES}

Um grupo de mães, elementos singulares de diversos subsistemas familiares, formam, em uma determinada Instituição, um grupo único, identificado por temas e vivências comuns. Na presente pesquisa, trabalhamos com um grupo de mulheres, solteiras ou casadas (referências sociais), mães biológicas ou de criação, de pacientes diagnosticados com transtornos psiquiátricos. O trabalho com essas mães, feito em seu contexto de tratamento, as coloca em um contexto de identidade com a doença de seus filhos, que é necessário para que possam refletir a seu respeito. Mas, para que o trabalho seja de crescimento e mudança, é necessário que haja momentos em que elas possam se "olhar de fora" para dentro do entremeado de relações (familiares ou com o grupo), de forma a diferenciarem-se do todo, responsabilizando-se.

A responsabilidade é o objetivo principal buscado com o trabalho de consciência corporal nesse grupo de mães. Com a conscientização de seus movimentos corporais e psíquicos, acreditamos que elas podem ter um maior contato consigo mesmas e com suas questões emocionais. A partir daí, montamos uma oficina de corpo em que fazemos movimentos (alongamento, aquecimento, toques etc.), que são conscientizados quando associados a uma definição verbal de seus conteúdos (sentimentos e sensações), surgidos como respostas às perguntas circuladas. Dessa maneira, melhoramos a qualidade de contato com nossos usuários e suas problemáticas.

A oficina de corpo, que serviu como objeto de pesquisa, foi criada no CAD (Centro de Atendimento Diário) do IPUB. No CAD existem diversas atividades, desde reuniões que trabalham no nível verbal, a oficinas que trabalham o corpo e todas as atividades têm o objetivo de atender tanto aos pacientes quanto aos seus familiares, juntos ou separadamente. 
A equipe do $\mathrm{CAD}$, em diversos momentos, demonstra ser imprescindível um espaço terapêutico dos pacientes com sua família, para o sucesso de seu tratamento. Isso, justificado pela fundamentação teórica da Terapia Sistêmica de Família, sugere o crescimento do pensamento Sistêmico no setor Institucional.

Desse modo, começamos a construir uma prática terapêutica com famílias, casais e sistemas íntimos que se sustenta conjugada aos pressupostos da teoria Sistêmica, tendo na visão holística uma das suas semelhanças com a GestaltTerapia. A questão teórica que se apresentou refere-se à contribuição possível da Gestalt-Terapia para a Terapia Sistêmica de Família.

A preocupação e a idéia de estimular a responsabilidade e a autoria nas mães, usuárias do CAD, partiu da observação de que, ao relatarem suas questões, elas costumam referenciá-las como oriundas da doença de seus filhos/sobrinhos, ou seja, tendem, em sua maioria, a responsabilizar os pacientes pela vida problemática que levam. Uma evidência desse fato ocorreu durante um atendimento de grupo: quando questionada pela terapeuta sobre como estava, uma mãe respondeu que estava "bem", emendando à resposta a narrativa do estado emocional e comportamental de seu filho. Em seguida, a terapeuta pergunta como ela poderia falar de si própria na história contada e a mãe volta a falar do filho. ${ }^{3}$ Isso mostra a dificuldade dessa mãe de falar de seus sentimentos ou de seu lugar na história que vive. Apesar de, na terapia verbal de grupo, o terapeuta trabalhar a fim de dar autoria à narrativa de cada familiar, eles demonstram dificuldades para seguir esse movimento. Partindo da dificuldade encontrada, acreditamos contribuir para o processo terapêutico do grupo, levando cada participante a um contato mais próximo consigo mesmo. Acreditamos que uma abordagem sobre o corpo proporciona um contato mais concreto com questões pessoais; que um espaço de silêncio, conjugado a um contato com o corpo, proporciona maior consciência de processo e, portanto, do lugar na história contada. E que, com um contato consciente de si, o sujeito pode narrar-se na primeira pessoa, colocando-se como responsável, ou seja, autor de sua vida. Nesse sentido, seguimos Maturana e Varela (1995), quando afirmam que constituímo-nos na linguagem. Desenvolvendo este assunto, os autores fundamentam os princípios de que construímos nosso mundo por meio da narrativa que fazemos dele. Assim, o que somos está contido em nossas histórias passadas e o que seremos dependerá das desconstruções e reconstruções que fazemos em nossa forma de olhar, em nossa narrativa. Somos "observadores na linguagem [...], porque se não estamos na linguagem não há reflexão" (MATURANA, 1998, p. 38, grifo nosso), não há conhecimento. Baseados nesses pressupostos, buscamos no grupo da oficina de familiares, estimular a assunção de responsabilidade de cada um no contexto de vida em que estão inseridos. Acreditamos que, dessa forma, a pessoa possui mais autonomia e, portanto, autenticidade na vida.

No momento em que partimos de nossos saberes para modificar um padrão de comportamento, vemos a ciência alcançando a vida cotidiana, o que, além de sinalizar o caráter do sistema instituído, pode provocar mudanças no próprio sistema. Como afirma Vasconcelos, "apesar de a maioria das pessoas não estar atenta ou não ter o hábito de pensar sobre o paradigma da ciência, é 
a ciência que embasa o viver em nossa cultura" (VASCONCELOS, 2002, p. 17). A autora, no mesmo texto, reforça sua afirmativa, dizendo já ser de Bertalanffy a idéia de que "a visão de mundo do homem da rua é obra de Newton, Locke, Darwin, Freud, mesmo que aquele nunca tenha ouvido falar desses" (VASCONCELOS, 2002, p. 18).

O que queremos dizer é que esperamos, com a prática da oficina, estruturada em saberes conjugados da Gestalt-Terapia com a Terapia Sistêmica Construtivista/Construcionista Social, modificar algo no discurso e nas vidas dos participantes dos grupos. Inseridos em um contexto de doença, queremos que possam falar de si de modo a transformar esse contexto e acreditamos que falar do próprio corpo e de seu uso é um bom caminho para isso.

\section{Enfoque Teórico}

Abordamos, em nossas análises, o conceito de circularidade de Cechin (PALAZZOLI et al., 1980), que já era usado nas reuniões dos grupos de familiares e, posteriormente, na oficina. Este conceito traz a idéia de que, ao fazermos a mesma pergunta feita ao paciente para os outros membros de sua família, ampliamos a perspectiva do olhar a doença, propiciamos um olhar para a doença como algo que pertence a toda a família, encontrando o papel de cada membro em sua manutenção.

Dessa forma, utilizamo-nos do processo de formular perguntas de Michael White (1988) que é também utilizado nas reuniões. Esse processo diz respeito à idéia de que não devemos dizer o que é certo ou errado, verdadeiro ou falso para os membros da família. Não devemos, nem podemos, dar uma resposta pronta para a resolução e seus problemas, mas sim ajudá-lo a descobrir uma nova forma de olhar e contar suas histórias. Assim, caímos na metodologia de Tom Andersen (1996) de refletir com famílias. Esta aparece não só no momento em que fazemos perguntas reflexivas, mas também sob a forma de um comentário que toque emocionalmente um membro ou grupo e assim possa ajudá-lo a refletir sobre suas questões. Tivemos o enfoque Sistêmico como condutor de todo o processo da pesquisa e nele trabalhamos com conceitos da Gestalt como:

- consciência ou awareness (POLSTER, E.; POLSTER, M., 1979, 2001): processo de aproximação (contato) com conteúdos psíquicos, sua forma, cor, cheiro, ou seja, com a dimensão total da pessoa.

- Conforme falam Polster, E. e Polster, M. (1979, p. 191) em capítulo intitulado "Consciência", "a cada conscientização sucessiva, a pessoa mais se aproxima da articulação dos temas de sua vida e também do movimento para a expressão desses temas".

- processo de contato e relação dialógica (YONTEF, 1998): contatar é o ato de uma pessoa reconhecer o que é seu elemento psíquico e o que é o do outro pelo movimento de conectar-se e afastar-se do outro. É pelo movimento que se tem consciência do processo da vida, do contrário ela se torna um hábito, mera 
repetição. Como diz Yontef (1998, p. 237), “o contato é o processo básico do relacionamento. Ele proporciona a verificação da diferença entre o self e o outro".

A Gestalt-terapia trabalha em uma dimensão dialógica, na qual a relação com o terapeuta é o início do tratamento por diálogo. O diálogo é uma forma de contato em que o "eu" está receptivo à auto-expressão do "tu" (outro), além de aberto a expressar o seu interior ao outro.

- e fenomenologia (ZINKER, 2001): Em Processo, Diálogo e Awareness, Yontef (1998, p. 236) afirma que a "fenomenologia é o método que a Gestalt-terapia usa para aprender a respeito do processo de awareness (consciência). [Busca tal compreensão] baseada no que é óbvio ou revelado pela situação (que inclui tanto o organismo quanto o ambiente), em vez da interpretação do observador". A fenomenologia influenciou na formação do método de conscientização da Gestalt. O método Gestáltico, originado de princípios da fenomenologia, é trazido por Zinker (2001; ZINKER; JOSEPH, 1979).

É importante ressaltar a importância de se respeitar o movimento do grupo no processo terapêutico. Para dar conta do entendimento desse processo, utilizamos as contribuições da abordagem Construcionista Social. A co-construção feita com conteúdos emocionais e interacionais, tanto da equipe quanto dos pacientes, impossibilitou-nos de antecipar detalhes do caminho traçado. Nosso fio condutor foi estar presente no processo, fazendo parte dele.

Esta pesquisa lançou-nos ao desafio de sistematizar alguns conceitos trazidos por elas, para que pudéssemos criar interlaces não somente vivenciais, mas teóricos. Essa conjugação foi feita, a nosso ver, na medida em que conjugamos elementos utilizados nas duas abordagens, em um novo espaço terapêutico. Com a composição dessa nova atmosfera, pudemos realçar os fundamentos sistêmicos da Gestalt, assim como a forma gestáltica da Terapia Sistêmica. Realizamos um trabalho que nos proporcionou olhar a interação dos elementos do sistema para além da expressão verbal. Não queremos dizer com isso que a Teoria Sistêmica não reconheça ou considere outras vias expressivas. O que entendemos é que a Gestalt tem um respaldo teórico, em termos de expressão do corpo, que pode fortalecer o tecido sistêmico, à medida que o reforça com indícios corporais, manifestações psíquicas, sejam emocionais ou intelectuais.

\section{FAzendo parte do Corpo da oficina (E dA OFICINA de CORPO)}

A oficina foi dividida em dois momentos. Um primeiro, de movimento corporal, e um segundo momento, de conversa sobre a experiência. Utilizamonos também da prática do alongamento com contato e consciência, de modo a preparar o corpo dos participantes para as atividades corporais solicitadas. 
A indicação para que participassem da oficina de corpo foi estendida a todos os membros usuários do grupo de familiares. O grupo da oficina começou compondo-se por seis mães, de modo a caracterizar-se como um grupo feminino. As questões de gênero, apesar de inevitavelmente estarem entrelaçadas na vivência em questão, serão tratadas nesses interlaces, não sendo destacadas das demais.

Tratamos, então, de um estudo de caso, em que foi necessário apurar as mudanças qualitativas das narrativas de membros da reunião de familiares, ocorridas após as práticas de atividades corporais. Esta oficina de práticas corporais teve duração de uma hora por sessão, contando com um momento de conversa que girava em torno de 20 minutos. Esse momento de conversa, que por vezes surgia no início da sessão, caracterizou-se mais por uma reflexão final das experiências vividas pelas integrantes do grupo. Os 40 minutos de trabalho corporal nas primeiras sessões foram de dinâmicas corporais. Estas surgiam de uma idéia inicial da coordenadora, baseada no contato anterior com os membros do grupo, somadas a seus interesses e possibilidades. As sessões tinham intervalo de 15 dias e aconteciam às quartas-feiras pela manhã, na semana seguinte à da reunião de familiares. A oficina teve seis meses de duração.

O procedimento metodológico de registro foi gravação em fita VHS, realizada na oficina que foi criada para as mulheres falarem de si mesmas, aproveitamos para realizar a pesquisa gravando suas imagens. Para a análise da experiência, foi necessária a gravação das sessões, visto que teríamos de registrar os movimentos corporais para associá-los aos conceitos utilizados. Assim, os conceitos de consciência, contato, relação dialógica e fenomenologia, trazidos pela Gestalt-Terapia, puderam ser vividos corporalmente pelos participantes e vistos novamente pela coordenadora, a fim de que pudessem fazer parte da análise final. As gravações, assistidas simultaneamente ao processo terapêutico, ajudaram também à coordenação do próprio processo, à medida que possibilitaram uma visão de fora e "do todo" do processo. A visão de fora, levando-se em consideração as diferenças, foi considerada em moldes semelhantes aos da reflexão de Andersen (1996). Após o estudo da fita de vídeo, que continha a sessão gravada, a coordenadora refletia sobre o movimento do grupo, imaginando um possível passo e sugerindo-o na sessão seguinte. Quanto à visão do todo, referimo-nos à visão geral do que foi a oficina para as mães participantes, não apenas em seu contexto de vida pessoal, como também no Institucional. Esta noção mais abrangente colocou-nos diante de vários questionamentos do âmbito da identidade corporal, "na" e "para" a instituição em questão. Questionamentos como, por exemplo: como podemos criar outros elementos para a identidade de nossos pacientes, que não só sua problemática mental? De que maneira se fará com que nossos pacientes tenham contato com a saúde em um campo visto como de doença? Tais questionamentos abrem espaço para o avanço do tema em pesquisas futuras. Para a análise dos resultados, então, foram utilizadas as observações feitas a partir dos relatórios escritos nas reuniões verbais dos grupos de familiares e das imagens em vídeo das sessões de oficina corporal. 
Observamos os efeitos da prática da oficina nas narrativas construídas nos momentos de conversa da oficina e detectamos possíveis influências em termos da assunção de responsabilidade por parte dos membros participantes das duas atividades em questão

Dessa forma, unindo essas duas abordagens em psicoterapia (Gestalt-Terapia e Terapia Sistêmica), seja trabalhando individualmente, em grupo ou em família, estamos dando movimento ao Sistema (que é um só, um todo interligado). Ajudando este sistema a crescer de modo mais saudável, estamos nos ajudando, já que fazemos parte deste sistema, o influenciamos e somos influenciados por ele.

\subsection{A oficina de Corpo EM Movimento: Conjugando E ADAPTANdo conceitos da Gestalt e da Terapia Sistêmica Construcionista}

Marcamos a primeira oficina para o dia 19 de junho de 2002, às 08h. Nilcéia foi a primeira a chegar. Logo depois chegaram Divina e Michele. Fizemos exercícios de respiração e aquecimento nas articulações do pescoço, ombros, quadril, joelhos e pés. Movimentando as respectivas partes do corpo, acreditamos dar mobilidade a todo o corpo, aumentando sua possibilidade expressiva. Além disso, aumentando a temperatura dessas partes, elas são sensibilizadas, oferecendo uma maior percepção de sua existência. Ou, seja, melhoramos a qualidade de contato com as respectivas partes corporais, fato que diz respeito ao contato consciente buscado pela Gestalt-Terapia. A conjugação e a adaptação dos conceitos das duas abordagens acontecem desde o movimento de sensibilização corporal. Este se torna propriedade para um contato consciente à medida que fazemos perguntas referidas a cada parte do corpo. As perguntas são feitas para todas as participantes simultaneamente, de modo a ter efeito semelhante ao das perguntas circulares. ${ }^{4}$ Perguntamos, por exemplo: como sentem o seu pescoço ao movimentá-lo? Relaxado, rígido, solto, preso etc. Fizemos a pergunta na primeira pessoa, para que cada membro do grupo pudesse concentrar-se melhor em suas próprias sensações. Em outro momento, pedimos que cada um observasse o movimento do colega e fizesse o mais parecido possível. Acreditamos que assim o colocamos no lugar do outro e permitimos também que este outro se veja de fora, experimentando um olhar mais reflexivo. Esse olhar de fora, usado na técnica de reflexão da Terapia Sistêmica, como vimos, vem posteriormente ao ato de fazer parte da experiência, que, no caso da oficina, esteve presente nos movimentos vivenciados por cada um. Assim, oferecemos a possibilidade de as participantes terem uma maior consciência de seus corpos e de si mesmas. Em seguida, pedimos para que se movimentassem conduzidas por cada uma dessas partes do corpo. Estimulamos a busca de diferentes caminhos para seus corpos percorrerem. A cada movimento, conduzido por diferentes partes do corpo, colocam-se em posições novas que terão novas e diferentes saídas encontradas. Elas devem seguir o fluxo de movimento respeitando a inteireza do corpo, pois, do contrário, não sairiam do lugar. A primeira sessão não foi filmada, pois precisávamos da autorização das integrantes, mas foram registradas experiências de destaque para cada uma delas: ${ }^{5}$ 
Nilcéia derrama lágrimas no exercício de respiração, além de, durante todo o tempo, permanecer com os olhos fechados. Tem dificuldade para respirar e afirma que sente falta de ar. Lembra-se de que nasceu com os olhos "colados" e teve de fazer um tratamento tópico para abrir os olhos.

Michele usou muito a cabeça como condutora dos movimentos sugeridos. Uma postura que nos chamou a atenção, no momento de conversa, foi o fato de ela ficar sempre muito preocupada com as colegas, cuidando pouco de suas dores. Aos poucos, na oficina, vinha-se queixando de dores nas costas e ombros. Passa-nos a idéia de que, por não falar de suas dores com palavras, acaba fazendo-o com o corpo.

Divina foi chamada à atenção por fazer os movimentos corporais muito rigidamente, como se os conduzisse. Percebeu isso ao olhar o movimento das colegas e compará-los ao seu. Aqui vemos, novamente, a tomada de consciência por meio do contato, mas um contato com o outro. Através da fronteira de contato entre a velocidade e o ritmo de seu corpo e o corpo do outro, Divina dá-se conta do controle que imprime nele e o quanto isto tem a ver com uma condução feita por sua cabeça (sua forma de pensar). Em um momento posterior (o momento de conversa final), diz que o que a incomoda é o desequilíbrio (já fez tratamento para labirintite) e nesse momento associamos esta preocupação com a forma como usa seu corpo ao movimentar-se. Divina controla-se para tentar manter-se equilibrada. No processo de conscientizar-se, construímos uma idéia: "controle", "cabeça", "desequilíbrio" (preocupação em estar equilibrada), todas essas palavras fazem parte da construção atual de Divina. Referimo-nos a uma construção, não só de sua narrativa, mas também de seu corpo. Pelas palavras, definimos seu movimento. Imaginamos que Divina possa, pelo movimento (experiências com o desequilíbrio corporal, por exemplo), re-construir sua relação de controle dela mesma e dos outros, expressando essas mudanças por meio de palavras. Este trabalho, que une fundamentos da Terapia Sistêmica Construcionista Social, com o contato consciente do corpo, foi levantado pela coordenadora como possibilidade de trabalho futuro. Não foi realizado por respeitarmos a dinâmica grupal. Divina não esteve presente na sessão seguinte e novas questões apareceram como figura.

\subsection{CO-CONSTRUÇÃO SOCIAL: CONSTRUINDO E CONSCIENTIZANDO-SE POR MEIO DA NARRATIVA DO CORPO EM RELAÇÃO AO OUTRO, AO ESPAÇO E AO SOM}

Em uma conversa sobre um trabalho corporal, em que foram orientadas a se mexerem, estimuladas pelo som de "Kitaro":6"

Michele conta que se remeteu à infância... "Viajando no som" (sic). Identificando um ponto de referência nessa fala, mesmo que em referência oposta, Divina conta que não se envolveu com a música colocada pela coordenadora, "não viajou". Usa o termo da colega e fazendo a oposição de palavras, diz que está sempre na "realidade", que é muito "pé no chão". Assim, lança mão das palavras de outra pessoa para definir sua própria identidade. Como fala McNamee (1998, p. 234), em seu artigo sobre construção comum de crise, "as alegações 
de formação de identidade e definição de crise não são construções individuais, o que é considerado um diagnóstico legítimo, e a cura subseqüente, também são produtos de construções colaborativas, interativas". Conclui que, dessa forma, mantém contato com o equilíbrio. Ao movimentar-se, busca o equilíbrio. Divina, pela narrativa de sua experiência corporal, conscientiza-se de sua forma de estar no mundo. Além disso, em sessões subseqüentes, chamo a atenção dela para o fato de que está sempre preocupada com o fato de estar fazendo os exercícios de maneira correta, apesar de a coordenadora já lhe ter dito que não há uma forma certa de fazer e sim a sua forma pessoal de movimentar-se. Essa preocupação é um elemento que caracteriza sua identidade.

\subsection{CONSCIÊNCIA PELO CORPO: CONSCIÊNCIA POR MEIO DE SENSAÇÕES, NA RELAÇÃO}

Uma nova participante da reunião de familiares é convidada a participar da oficina. Seu nome é Valéria. Seu sofrimento, expresso na reunião, era seu filho Paulo, que não saía do computador, de dentro de seu quarto imundo. No primeiro dia de oficina estava muito aflita. Seu trabalho corporal partiu da dificuldade de sua colega Michele em mexer e relaxar a bacia. Todo o grupo movimenta-se em torno da dificuldade de um membro. Esta é uma atitude que observamos também na reunião do grupo de familiares. Diante da dificuldade de um membro, os outros buscam se identificar; buscam em si a semelhança com o próximo, na tentativa de encontrar sua identidade, enquanto grupo, e sua individualidade.

Valéria deita-se e começa a tentativa de mexer a bacia. A coordenadora, percebendo sua dificuldade, tenta ajudá-la colocando as mãos na bacia. Percebe sua rigidez nos ombros e então pede que respire. A entrada de ar em seu pulmão estende os tecidos de toda a caixa torácica, ativando também a circulação sanguínea de toda essa área emocional. Valéria faz contato. Nesse instante, coloca as mãos na testa e conta sobre um estupro que sofreu aos 16 anos. A coordenadora lhe pergunta como deve fazer para se sentir mais segura; sugere que se sente e Valéria concorda que dessa forma sente-se melhor. A participante, por meio do contato que fez com a relação de contato presente entre seu corpo e o corpo do outro (coordenador), rememorou acontecimentos antes tidos como sem importância para seu estado emocional. Estava fisicamente em uma posição vulnerável, diante da coordenadora, e a mudança de postura corporal foi o princípio de uma atitude para se sentir mais protegida. Por meio da tomada de consciência da questão, Valéria, juntamente com o grupo, reconhece sua necessidade de ajuda. $\mathrm{Na}$ semana seguinte dá início a um tratamento psicológico individual. Aos poucos, a cada reunião de familiares, traz-nos a notícia de que Paulo tem melhorado sua relação com ela e até consigo mesmo, suas coisas, seu quarto. A visão holística e sistêmica que acompanha ambas as abordagens é o que fundamenta a mudança mais abrangente no sistema familiar. Se entendermos que o sistema é um todo interligado, acreditamos que mudanças ocorridas em um elemento do sistema irão interferir em todo ele. Dessa forma, trabalhar com a família, muitas vezes é trabalhar com um de seus membros. 


\subsection{REFLEX̃̃o NA RELAÇÃo DIALÓGICA: UM CAMINHO PARA A SOLUÇÃO DE PROBLEMAS CONCRETOS}

Em uma sessão em que participaram apenas duas pessoas, pudemos ver, de forma simples, o diálogo estabelecido na relação. Michele, a primeira a chegar, conta-nos que Tamara pediu ajuda a ela e às outras colegas, para ir até a casa de sua filha para interná-la à força (sairiam após a prática da oficina). Michele afirma que está muito sentida por terem decidido negar tal ajuda. Acharam que não era adequado, já que a filha de Tamara nem as conhecia. Michele não sabia como informá-la sobre a decisão que tomaram; temia que Tamara ficasse chateada com ela e as outras colegas, que não viriam. Enfim, Tamara chegou atrasada, com a sessão já começada, com a participação individual de Michele. Começamos fazendo um aquecimento. Tamara, ao chegar, inseriu-se no trabalho, que proporcionou a cada uma um maior contato com seus corpos, em separado. Pedimos que cada uma fechasse os olhos e respirasse profundamente. Pedimos também que mexessem os pés, percebendo o movimento de contato com o chão e que em seguida mexessem todo o corpo. Pedimos para que cada uma sentisse o que veio fazer no encontro. Continuamos um trabalho de contato, no qual as participantes tocavam cada uma seu próprio corpo. Pedimos que sentissem, cada uma, o que gostariam de receber da outra e expressassem com o corpo este desejo. As duas se olham e se dão um abraço. Dizemos a elas para sentirem o que precisam fazer e deixarem que isso aconteça. Michele deita-se e Tamara senta-se. Em seguida, damos papel e lápis de cera. Foram orientadas a expressarem o que viveram naquele espaço. Sem olharem uma para o desenho da outra, fizeram as duas o desenho de um sol vermelho. Michele fala de seu sol, dizendo que chegou sombria e o sol representava o brilho da luz que foi aparecendo (“A esperança existe!", diz ), no momento em que abraça Tamara. Afirma que percebeu, ao deitar, que precisava de tranqüilidade para caminhar na vida. Tamara, que fez um sol, não só vermelho, mas azul. Conta que o sol é a "esperança, a claridade interior". Questionamos a ambas sobre o vermelho presente nos dois desenhos e responderam juntas que diz respeito à "energia que todos precisamos". Tamara conta que chegou muito confusa, mas o relaxamento a ajudou a sair da confusão. Acha que deve relaxar um pouco. De forma abrangente, pudemos ver o diálogo corporal travado entre as duas participantes. Diálogo em que ambas estavam atentas a seus sentimentos e sensações e, dessa forma, puderam estar atentas ao lugar em que estavam na relação. Da relação de sofrimento em que se encontravam puderam encontrar-se, cada uma isoladamente, para depois se encontrarem entre si, de forma autêntica e responsável. As duas percebendo-se na necessidade de relaxar. O relaxamento é um momento em que se pára de agir, para prestar atenção em coisas como cores e sons. A atenção voltada para elementos como esses remetem-nos para a abstração do problema. A possibilidade de representação do problema/solução em cores, por exemplo, permitirá a transformação abstrata, para, em seguida, abrir-nos a uma transformação concreta, para a solução de um problema. As participantes, com um espaço de relaxamento em que puderam se olhar, uma a outra e a si mesma, dialogaram, sem ao menos precisarem falar uma com a outra para concluírem os discursos em questão. A própria falta das outras duas participantes já dizia 
sobre a escolha que fizeram em não participar da internação da filha de Tamara. O diálogo proporcionou um entendimento na sessão, ao estabelecerem contato com seus sentimentos e sensações.

Nossa proposta de pesquisa proporcionou o experimento de uma nova dimensão para a prática da Terapia Sistêmica de Família: a dimensão corpo. Esta experiência estimulou em cada participante o encontro consigo, de forma a poderem se mostrar mais singularmente, inclusive nas reuniões do grupo de familiares. As participantes, na avaliação da oficina, falaram do fato de poderem hoje se relacionar melhor com seus corpos e sensualidade. Elas têm uma nova forma de olharem para si e para os outros, na rua. Uma nova forma de tocar seu próprio corpo, cuidando dele e descobrindo-o.

Nas reuniões dos grupos de familiares, surpreendemo-nos com as mudanças ocorridas, principalmente com as duas mães, Valéria e Nilcéia, que não estavam bem, no início da oficina. Surpreendemo-nos com Valéria, que pôde cuidar de si (sendo também cuidada nos dois grupos), resolvendo fazer terapia individual, e com Nilcéia, que, na avaliação da oficina, disse ter entrado em contato com sua feminilidade. Nilcéia surgiu com uma nova questão no grupo de reunião verbal. Pôde falar sobre o quanto não está bem, em sua relação com o marido (marido deixa de ser fundo e passa a ser figura). Como muitas mães, se escondia atrás dos problemas referentes a seu filho. Continua a ter problemas com ele (usuário de drogas), mas, no momento, não se impede de cuidar de outras questões que precisa tratar para ficar bem.

\section{CONSIDERAÇões FINAIS}

Somos, como foi falado anteriormente, remetidos à visão holística que nos permite entender a expressão do corpo como linguagem em um contexto social. Neste trabalho, pudemos conjugar pensamentos a respeito da expressão lingüística e corporal. Encontramos nossa própria forma de pensar o homem, como um ser que se faz no uso do corpo e da linguagem. Nosso trabalho exigiu atenção, presença, contato e criatividade, tanto da equipe, quanto dos usuários. Acreditamos que foi, também, um trabalho que proporcionou, a todos os participantes, uma maior e especial qualidade de atenção, presença, contato e criatividade. Não tivemos expectativa de que este fosse um trabalho simples, muito menos de que formasse um todo perfeito e definitivo, mas apenas queríamos contar com um elemento a mais para a comunicação e a identidade das pessoas envolvidas. Dessa forma, esperamos, trazer, para os usuários do IPUB, uma forma mais integrada de criar identidade junto à Instituição. Imaginamos, pelo menos, que estamos avançando na tentativa de oferecer uma alternativa à dicotomia corpo/mente. Conquista esta que seria mais simples se diminuíssemos a importância da mente e pensássemos mais no corpo, já que aquela faz parte deste. Esta seria uma das importantes indicações de pesquisas posteriores que o nosso trabalho apresenta. 
A Gestalt tem uma forma de olhar a pessoa como um todo. Assim, aprofundamos suas questões existenciais, compreendendo-as no aqui-e-agora em todos os seus aspectos. Todas as formas de expressão (artística, corporal, verbal etc.) são meios de compreensão da pessoa. Portanto, o terapeuta pode entender melhor o significado das questões trazidas pelo cliente.

A Terapia Sistêmica tem um olhar para o sistema mais amplo, em que está inserido o sujeito. Um olhar que vê o mundo em volta. Entende-se aqui que o sujeito é social e parte do que está sendo ou vivendo está nas suas relações com o mundo. O olhar sistêmico, então, permite-nos ver a vida da pessoa, sua relação na família e na sociedade, como coisas integradas, unidas, relacionadas.

A Gestalt aprimora-se em um trabalho de consciência do corpo, do comportamento, dos sentimentos e sensações. Em contrapartida, a Teoria Sistêmica aprimora-se na compreensão das inter-relações existentes entres os sujeitos e com o mundo. $\mathrm{O}$ que o entrecruzamento dessas duas práticas vai nos trazer é uma maior qualidade de consciência de quem somos e como somos no mundo. Neste processo de compreensão, assumimos a autoria de nossa própria história e nos permitimos mudar, o que é necessário para alcançar nossos objetivos por um caminho mais feliz.

Diante do que foi explicitado, podemos aprofundar o encontro dialógico das duas abordagens, fazendo uma analogia entre a idéia de "diálogo" de ambas. O diálogo, tendo o propósito de construção, considera a tomada de consciência e a reflexão como complementos importantes para a mudança. Elementos complementares que dialogam, dando-nos um resultado novo, diferente.

A tomada de consciência, importante conceito da Gestalt-terapia, esteve relacionada, na prática, à idéia de reflexão proposta pela Terapia Sistêmica. Os grupos de familiares indicaram um caminho possível para a tomada de consciência por meio do trabalho corporal, possibilitando uma maior elaboração daqueles que participaram deste trabalho. As mulheres que freqüentaram a Oficina de Corpo puderam participar mais efetivamente das reflexões dos grupos de familiares. Ao cuidarem de si, entrando em contato com o seu corpo, tomaram consciência de importantes aspectos de sua relação subjetiva com o mundo no qual vivem. Como conseqüência, na oficina do corpo, pudemos conciliar as duas abordagens, influenciando a busca de uma nova posição nos grupos de familiares.

$\mathrm{Na}$ técnica de fazer perguntas, utilizada tanto nos grupos de familiares quanto na oficina de corpo, reconhecemos tanto a reflexão quanto a tomada de consciência. Consideramos que ambas estão relacionadas e contribuem para um trabalho mais efetivo. É necessário, entretanto, que haja um maior aprofundamento teórico na relação desses dois conceitos, já que pensamos que um processo de reflexão não é necessariamente acompanhado de uma tomada de consciência.

A reflexão da Terapia Sistêmica caracteriza-se por ser uma reflexão de fora, isto é, após um momento de ouvir e sentir, a reflexão é realizada pela equipe reflexiva, enquanto a família e o terapeuta de campo ouvem, para, em seguida, comentarem a reflexão. Já a tomada de consciência da Gestalt é experimentada 
de dentro para fora, no olhar e sentir o próprio movimento no processo. Por isso, ao fim deste trabalho, perguntamo-nos sobre as implicações teórico-práticas desta diferença de movimento. Não vemos como uma oposição e sim como propostas diferenciadas que na nossa prática foram complementadas. Por exemplo: quando sugerimos que um corpo olhe o outro se movimentar como se fosse o seu, trabalhamos a consciência de fora para dentro. Assim, inserimos aquele que observa em um momento de envolvimento, seguido de reflexão de todos no grupo. A reflexão é importante como um trabalho de elaboração de novas perspectivas, mas uma indagação deve ser feita: quando a reflexão (de fora) torna-se uma tomada de consciência (de dentro)? Seria preciso continuar pesquisando.

Vemos que muitas composições podem ser criadas com esses dois conceitos e com a técnica de fazer perguntas. Sugerimos que tanto um trabalho relacional, realizado pela equipe e proposto pela Terapia Sistêmica, quanto a tomada de consciência, que se centra na subjetividade, podem constituir uma abordagem terapêutica. Desse modo, deixamos nossa experiência como um exemplo de construção, na comunhão dessas duas abordagens. Acreditamos que outras composições possam ser feitas e bons trabalhos possam ser realizados na descoberta dos processos de conhecer e mudar o próprio mundo.

\section{Notas}

${ }^{1}$ Este método segue o conceito de circularidade de Cechin (PALAZZOLI, M. et al., 1980), que acredita que fazendo as mesmas perguntas circularem por todos os membros da família, propiciamos, nós terapeutas, um espaço de reconstrução da "verdade" desse grupo.

${ }^{2} \mathrm{Na}$ terapia Sistêmica o método de formulação de perguntas foi criado por Michael White (1998) e tem como objetivo estimular a reflexividade, além de informar aos membros presentes a respeito do sujeito questionado.

${ }^{3}$ Dados retirados do caderno de relatórios feitos simultaneamente aos atendimentos de grupo de familiar do CAD (relatório do dia 27 de maio de 2002).

${ }^{4}$ Caracterizadas, na Terapia Familiar Sistêmica, como uma mesma pergunta feita a diferentes membros da família.

${ }_{5}^{5}$ A quarta participante referida para a análise final da pesquisa entrou na quarta sessão da oficina, tratando-se também de um novo membro da reunião de familiares.

${ }^{6}$ Grupo musical indiano. 


\section{REFERÊNCIAS}

ANDERSEN, T. Processos reflexivos. Tradução: Rosa Maria Bergalo. Rio de Janeiro: Instituto NOOS; ITF, 1996.

MATURANA R., H.; VARELA, F. G. A árvore do Conhecimento. Campinas, SP: PSY II, 1995.

MATURANA R., H. Emoções e Linguagem na educação e na política. Belo Horizonte: UFMG, 1998.

MCNAMEE, S. A reconstrução da identidade: a construção comum da crise. In: MCNAMEE, S.; GERGEN, K. J. (Org.) A terapia como construção social. Porto Alegre: Artes Médicas, 1998.

PALAZZOLI, M. et al. Hypothesising, circularity, neutrality: three guide lines for the conductor of the session. Family Process, [S.1.], v.19, n. 1, p. 3-12, 1980.

POLSTER, E.; POLSTER, M. Gestalt-terapia Integrada. São Paulo: Summus, 2001. . Belo Horizonte: Interlivros, 1979.

VASCONCELlos, M. J. E. de. Pensamento Sistêmico: o novo paradigma da ciência. São Paulo: Papirus, 2002.

WHITE, M. O processo de formular perguntas: uma terapia de mérito literário. Tradução: Mônica Rego. Rio de Janeiro: ITF-RJ, 1998. 14 f. Arquivo de textos.

YONTEF, G. M. Processo, diálogo e awareness: ensaios em Gestalt-terapia. São Paulo: Summus, 1998.

ZINKER, J. C. A busca da elegância em psicoterapia. São Paulo: Summus, 2001.

ZINKER, J. C.; JOSEPH, C. El processo criativo en la terapia gestáltica. Buenos Aires: Paidos, 1979.

Recebido em: setembro de 2003

Aceito em: novembro de 2005 